Gut, 1981, 22, 512-527

Progress report

\title{
Response of the intestinal mucosa to ischaemia
}

The small intestinal mucosa is particularly sensitive to ischaemia, but it also possesses a tremendous regenerative potential. The mucosa of the colon is less easily destroyed by a reduction in the blood supply, but, once damaged, it recovers more slowly. In these pages we shall review the various structural and functional studies, performed in experimental animals, that have contributed to our understanding of the response of these epithelia to different degrees of ischaemia.

\section{Disruption of small intestinal mucosa during ischaemia}

Structural damage to the small intestinal mucosa is observed remarkably rapidly after the onset of an ischaemic accident. Ultrastructural investigations have revealed alterations in the microvilli of the cells at the villus tips three to five minutes after the onset of total circulatory arrest affecting a loop of rat or dog small intestine. ${ }^{1-3}$ At the light microscope level, the first visible lesions consist of a detachment of the cells, particularly in the apical regions of the villi, from the basement membrane, with the formation of subepithelial blebs. ${ }^{4-6}$ Numerous authors have described the development of the morphological changes in the small intestinal mucosa on prolongation of the ischaemic trauma, both with the aid of the light microscope ${ }^{4-9}$ and with the electron microscope. ${ }^{12610}$ After a total ischaemia of 30 minutes in the rat or of 60 minutes in the dog (Figure), the upper two-thirds of the villi are completely denuded of epithelial cells, whereas the lower reaches of the villi and the crypts remain relatively intact. ${ }^{911}$ Certain investigators have claimed that rat crypt cells are already damaged after an ischaemia of 30 minutes, ${ }^{5}$ whereas others have reported lesions in these structures only after a circulatory arrest of one hour ${ }^{12}$ or even two hours. ${ }^{13}$ With this single exception, there has been good agreement between the different groups of investigators on the course of mucosal destruction; only those authors who left the collateral circulation in$\operatorname{tact}^{14}$ have described a markedly slower rate of tissue disruption. The structural alterations that occur in the intestinal mucosa during shock are similar to those observed in acute ischaemia, as the splanchnic circulation is greatly reduced in such circumstances.

Fewer investigations have been devoted to functional studies of the mucosa during ischaemia, but those which exist have emphasised the good correlation between structural and functional characteristics after this trauma. Guthrie and Quastel ${ }^{15}$ published the first study of the function in vitro of an intestine excised from a guinea-pig suffering from shock or of an intestinal loop that had been rendered ischaemic for 
one hour. In both cases, the movement of glucose across everted sacs prepared from such intestines was greatly reduced. In rats, an intestine subjected to 30 minutes' ischaemia has lost almost all capacity to accumulate sugars and amino-acids against a concentration gradient in vitro ${ }^{59}$ in the same vein, dog ileal mucosa is unable to transport these two substrates actively after an ischaemic trauma of one hour. ${ }^{11}{ }^{16}$ In the same experimental model, we have described the abolition of glucose absorption by the intestine in vivo and the development of an important net secretion of water and electrolytes across the damaged mucosa. ${ }^{16}$

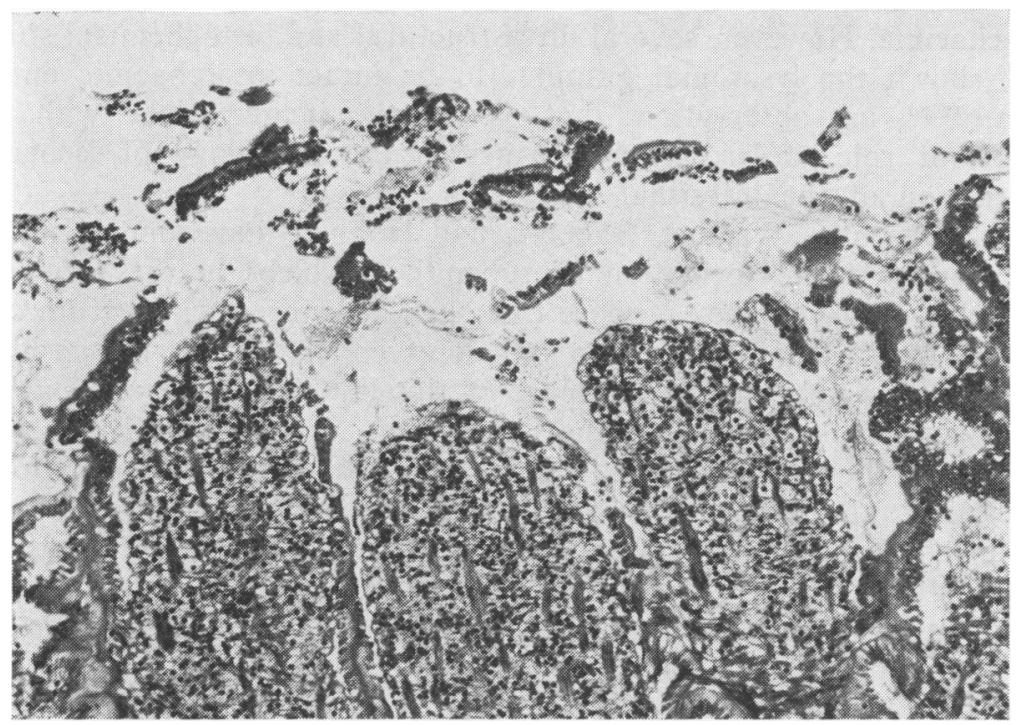

Figure Histological picture of the villi of dog intestinal mucosa immediately after one hour's acute ischaemia, showing desquamation of the epithelium from the villus tips. $H$ and $E, \times 110$.

The specific activity of certain enzymes in the damaged mucosa has also been examined on occasion. Gabbert et al. ${ }^{12}$ employed histochemical techniques to show that cells desquamated into the intestinal lumen during the first phase of mucosal destruction nevertheless maintained normal enzyme levels. After longer periods of ischaemia, histochemically demonstrable brush-border enzymes, such as alkaline phosphatase and leucine aminopeptidase, are reduced in $\operatorname{dog}^{16}$ or rat $^{2}$ intestinal mucosa. The specific activity of sucrase, determined biochemically, is concomitantly reduced. ${ }^{17}$ It has been pointed out that brush-border enzyme activities are the most rapidly affected after the onset of ischaemia;18 19 the specific activity in microsomal fractions of sodium-potassium-ATPase, generally localised in the basolateral membrane of the enterocyte, ${ }^{20}$ is unchanged after an ischaemia of one hour ${ }^{11}$ but reduced after a trauma lasting two hours. ${ }^{21}$

The mechanism of the rapid destruction of the intestinal mucosa is a matter of debate. According to a hypothesis that was formerly rather popular, the production of lactic acid in the cytoplasm as a result of anaerobic glycolysis caused an abrupt reduction in the intracellular $\mathrm{pH}$. This, in its turn, provoked a disruption of the lysosomal membranes 
and a liberation of acid hydrolases into the cytoplasm. These would then attack the plasma membrane of the cell and lead to its destruction. Two observations would appear to support this idea: first, the mature cells at the villus tips contain the largest number of lysosomes, a fact that could explain their preferential sensitivity to ischaemia;22 and, secondly, intestinal ischaemia is accompanied by a pronounced liberation of lysosomal enzymes into the blood, ${ }^{21}{ }^{23} 24$ the lymph, ${ }^{25-27}$ and the intestinal lumen. ${ }^{16} 28$ In addition, the ratio of free to bound lysosomal enzymes in the mucosa of ischaemic intestine is increased, ${ }^{29}$ testifying to a liberation of such enzymes from their granules during the course of ischaemia. However, several ultrastructural and histochemical studies have shown the lysosomal granules to be intact in ischaemic enterocytes, ${ }^{1216}$ an observation that is clearly incompatible with any important role of lysosomal enzymes in the pathology of ischaemic destruction of the intestinal mucosa.

More recently, Wagner, Gabbert, and $\mathrm{Höhn}^{6}{ }^{30}$ have underlined the importance of the formation of subepithelial blebs in the genesis of ischaemic damage. They propose that such blebs are formed from cytoplasmic fluid accumulation in a cell deprived of energy as a result of the ischaemia, and that the seepage of this liquid into the subepithelial spaces causes detachment of the enterocytes from the basement membrane. It is thus proposed that the cells are desquamated intact into the intestinal lumen where they are later destroyed by the hydrolases of the intestinal juices. Histochemical and ultrastructural evidence is supplied in favour of this hypothesis, ${ }^{6}{ }^{12}$ which nevertheless fails to explain satisfactorily why the cells at the tips of the villi are most vulnerable to ischaemic crises.

A third mechanism for the disruption of the intestinal mucosa has been developed by Bounous and his associates, who have assigned a role to the proteases of the intestinal contents in the breakdown of mucosal structure. ${ }^{18}{ }^{31}$ They suggest that the first stage of epithelial disintegration involves the action of luminal factors, particularly elastase, on the brush-border membrane proteins, leading to their loss into the lumen. It is suggested then that under anoxic conditions these proteins cannot be replaced in a normal fashion, so that the underlying structures become accessible to the digestive actions of other luminal enzymes, such as trypsin and chymotrypsin. This attractive idea, which receives support from experiments in which specific inhibitors have been instilled into the lumen, presupposes a tremendous turnover rate for brush-border proteins, as the normally oxygenated enterocyte is expected to replace these elements with the same rapidity as that with which they are destroyed by luminal hydrolases; the experiments with ischaemic intestine have shown how rapidly brushborder proteins can be disrupted, but there is no evidence in normal intestine that they can be replaced at such a speed.

\section{Regeneration of small intestinal mucosa after ischaemic damage}

The recovery of the intestinal mucosa after an ischaemic trauma is remarkably rapid. One day after a total ischaemia of one hour's duration, the villi of dog ileum are once again covered with an almost 
normal epithelium, which contains only rare defects at the villus tips. ${ }^{11}$ In the rat, after ligation of the superior mesenteric artery for one hour, recovery of normal structure occurs within 48 to 72 hours. ${ }^{32}{ }^{33}$ When the ischaemic period is prolonged to two hours, the structure of both villi and epithelial covering requires seven days to return to normal, both in the rat $^{30}$ and in the dog. ${ }^{21}$ Glotzer et al. ${ }^{8}$ subjected loops of canine small intestine to longer periods of acute ischaemia, and demonstrated that the mucosa was capable of recovering after traumas lasting up to seven hours. This observation is clearly of clinical interest, as it shows that, in cases of mesenteric thrombosis or embolism, it is reasonable to hope for recovery of the intestine after surgical intervention on the obliterated vessel, provided that the operation is performed as rapidly as possible. ${ }^{34}$ As far as the restoration of function is concerned, there is generally a close correlation between the absorptive capacity for organic solutes in vitro and the morphological state of the tissue. ${ }^{51621}$ Table 1 illustrates the course of recovery of phenylalanine and $\beta-$ methyl-glucoside transport in dogs after a total acute ischaemia of two hours; there is partial recovery after three days, with cnly sugar transport differing significantly from the control value, and full recovery seven days after the trauma. The restoration of normal water and electrolyte absorption in vivo, determined by perfusion techniques, is retarded with respect to the transport of amino-acids and sugars, either in vitro or in vivo ${ }^{16}$ this phenomenon will be discussed more fully below.

It is interesting that the regeneration of the mucosa is not influenced by intraluminal environmental factors; in a study designed to reproduce strangulation occlusions, Mirkovitch et al. ${ }^{35}$ created a mechanical occlusion in the small intestine of dogs, and then, four days later, submitted a loop of the occluded intestine to an ischaemia of one hour. They were able to demonstrate that, even in the presence of the noxious obstruction fluid, the mucosa was capable of recovering its structure and function within 24 hours-that is to say, with the same rapidity as an intestine without a simultaneous occlusion.

The speed of recovery of the small intestinal mucosa is such that certain problems of interpretation arise, as has been discussed in a recent work $^{5}$ where the early phases of regeneration of the rat small intestinal mucosa were studied after an acute ischaemia of 30 minutes. At this stage, the epithelium of the upper two-thirds of the villi had been desquamated into the lumen and the tissue was no longer capable of actively transporting organic solutes during an incubation in vitro. How is it possible that new villi can be formed in less than 24 hours, when the life-span of a normal enterocyte migrating from the crypts to the villus tips is at least 36 hours? ${ }^{36}$

Even if we assume, along with certain investigators, ${ }^{23037}$ that the crypts of the damaged intestine are the site of accelerated proliferation, the cells that cover the new villi can hardly have originated from the crypts. We are forced to conclude that the cells remaining on the lower third of the villi, even if temporarily functionless at the end of the ischaemic trauma, play an important role in the re-epithelialisation process. This interpretation presupposes, first, that the lack of function 


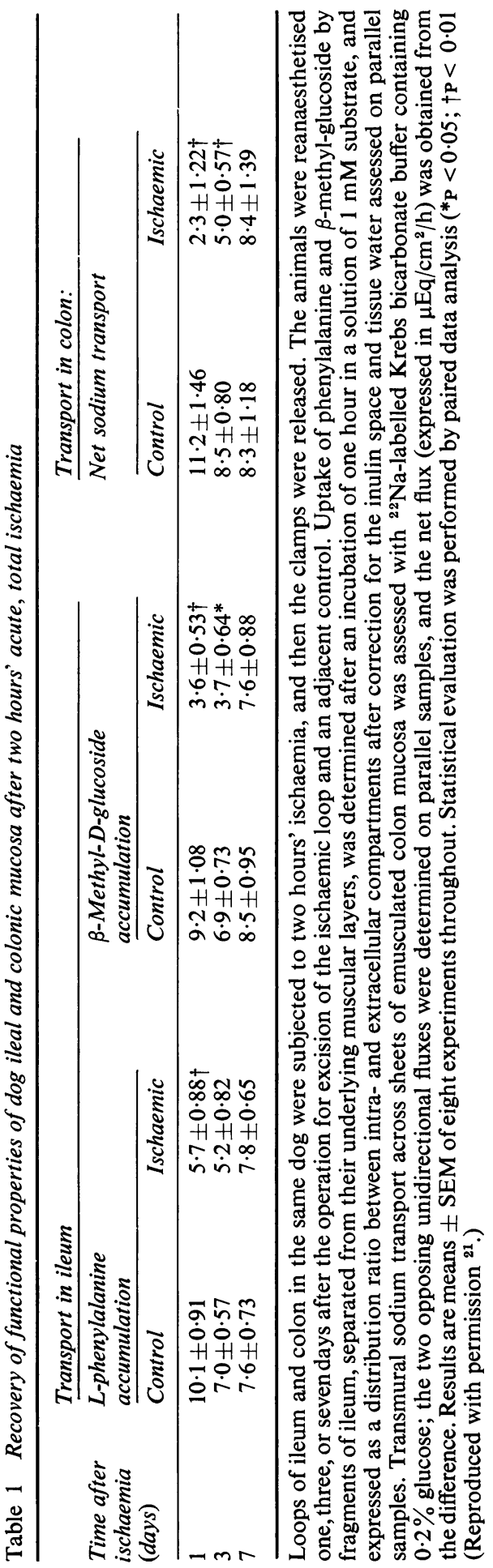


of these cells simply reflects a reduction in the cellular energy that would be necessary for the active transport processes, a situation which could be reversed by the reintroduction of oxygen into the system, and, secondly, that these cells have not yet been detached from the lamina propria by bleb formation. With the aid of these two suppositions, we have developed a model to explain the re-establishment of normal villus structure after temporary ischaemia. In the first phase, the defects at the villus tips are closed up by the cells that remain on the lower reaches of the villi. In this way, a new and unbroken epithelial covering will be generated very rapidly, but the end result will be the formation of the stunted villi that have often been observed in the early stages of mucosal recovery after acute ischaemia. ${ }^{16}$ In a second phase, the new villi proceed to lengthen by means of a parallel regeneration of the epithelium and the elements of the lamina propria, with the participation, at this stage, of new cells supplied by the crypts. ${ }^{5}$

\section{Protection of mucosa against effects of ischaemia}

It has been known for some time that the introduction of a buffered, glucose-containing solution into an intestinal loop during an ischaemic trauma affords at least a partial protection against the effects of the anoxia. $^{3498^{-41}}$ Several hypotheses have been developed to explain this protective action. Bounous ${ }^{42}$ proposed that the fluid introduced acted simply by rinsing out the intestine and eliminating from the lumen pancreatic proteases and bile salts which could play a role in the pathogenesis of the intestinal lesions, as has been explained above. $A$ priori, the observation that the intestinal mucosa can be protected by perfusion with almost any physiological solution would appear to provide support for this idea. In a series of dogs, we examined the protective action afforded by a number of media, and found that even perfusion with an isotonic mannitol solution during the ischaemic period afforded a significant protection of the mucosa against the noxious effects of the trauma. ${ }^{40}$ However, the use of a glucose-containing buffered solution was somewhat more effective, as had been shown by other investigators ${ }^{38} 43$ who proposed that the glucose introduced into the lumen supplied energy to the damaged mucosa. On the other hand, a different light was thrown on this problem by Åhrén and Haglund. ${ }^{39}$ They demonstrated that the oxygen dissolved in the fluid introduced into the lumen was the decisive factor in the protection of the mucosa against ischaemic damage, as the instillation of a solution saturated with nitrogen afforded no protective effect. Their point of view was supported by the experiments of Shute, ${ }^{44}$ which disclosed a protective action of gaseous oxygen injected into the lumen of the ischaemic intestine.

We have recently re-examined this problem in a series of experiments with rats ${ }^{41}$ and demonstrated clearly that, in this species, both oxygen and glucose play a role in the protection of the mucosa, as illustrated in Table 2. However, it should not be forgotten that the rat intestinal mucosa is the site of a considerable anaerobic glycolysis which is capable of supplying a substantial quantity of energy to this tissue. ${ }^{45}$ Other species possessing less important glycolytic mechanisms might not react so 
Table 2 Protection of rat intestinal mucosa against effects of ischaemia

\begin{tabular}{lll}
\hline Loop & Solution introduced & $\begin{array}{l}\text { Uptake of phenylalanine } \\
\text { ( } \mu \text { mol/100 mg fresh tissue) }\end{array}$ \\
\hline Control & None & $0.64 \pm 0.036$ \\
Ischaemic & None & $0.20 \pm 0.026$ \\
Ischaemic & Oxygenated buffer without glucose & $0.49 \pm 0.073$ \\
Ischaemic & Nitrogenated buffer without glucose & $0.18 \pm 0.026$ \\
Ischaemic & Oxygenated buffer with glucose & $0.77 \pm 0.041$ \\
Ischaemic & Nitrogenated buffer with glucose & $0.46 \pm 0.069$ \\
\hline
\end{tabular}

Loops of rat ileum were rinsed with the solution stated, then subjected to 15 minutes' total ischaemia by clamping the afferent mesenteric vessels and the collaterals at each end of the loop. Immediately after the ischaemia, the loop was excised and cut into rings for the determination of the accumulation of ${ }^{14} \mathrm{C}$-L-phenylalanine $(1 \mathrm{mM})$ during an incubation of one hour at $37^{\circ} \mathrm{C}$. Each value is the mean \pm SEM of eight determinations on different rats. (Reproduced with permission. ${ }^{41}$ )

favourably to a solution with glucose but without oxygen. Nevertheless, the present observations indicate clearly that the introduction of glucose without oxygen or oxygen without glucose, partially protects the rat intestinal mucosa, whereas a combination of the two factors is considerably more effective.

\section{Source of secretion of water and electrolytes across ischaemic mucosa in vivo}

It has been demonstrated on several occasions that a net movement of water and electrolytes from the blood to the lumen across the damaged mucosa of dog small intestine develops after an acute ischaemia of one hour. ${ }^{16}{ }^{46} 47$ A similar secretion has been described in the intestines of animals subjected to haemorrhagic shock. ${ }^{48}$ The extent of this response depends on the degree of morphological damage, as the secretion may be reduced or even prevented by protection of the intestine through the introduction of an oxygenated solution containing glucose into the lumen during the ischaemic crisis. ${ }^{40} 46$

In an attempt to explain this phenomenon, Cook, Wilson and Taylor ${ }^{48}$ suggested that the fluid shift occurs by virtue of 'filtration flow' due to the hydrostatic pressure difference across the damaged mucosa. For two reasons, we consider this explanation rather unsatisfactory. In the first place, we demonstrated obstruction of the villus capillary circulation immediately after acute ischaemia of dog ileum, ${ }^{11}$ so that movement of fluid across the capillaries of the villus core would seem rather unlikely. Secondly, phenol red injected into the vascular bed of a dog was shown to be unable to pass into the lumen of the ischaemic intestine, ${ }^{49}$ an observation that suggests that the passage of water and electrolytes towards the lumen does not occur by a passive process. Nevertheless, other authors have reported, particularly after prolonged ischaemia, an enhancement of the passage in either direction across the damaged mucosa of macromolecules or substances to which the epithelium is normally impermeable;24 5051 such observations would indicate that ischaemia does indeed cause the loss of a specific intestinal barrier. Reconciliation of these contradictory findings is difficult, as different species and different periods of ischaemia were used in the various studies. 
In a recent publication, ${ }^{17}$ we proposed an alternative explanation for the phenomenon of net loss of water and electrolytes after ischaemia. Our hypothesis is based on the observation that the crypts of dog intestine apparently remain intact after an ischaemia of one hour, the principal lesions affecting the mature cells at the villus tips. We suggest that, in the normal intestine, the crypt cells secrete sodium and water towards the lumen, whereas the mature enterocytes have an absorptive function, so that they reabsorb the fluid and electrolytes secreted in the crypts. We believe that, during the maturation process, a secretory cell is gradually transformed into an absorptive element through the development of its enzymatic machinery. An important feature of the hypothesis, however, is that both crypt and villus cells possess both absorptive and secretory functions; it is simply the quantitative relationship between them that changes during maturation. When this model is applied to the functional changes that occur after acute ischaemia, we see that the intact crypt cells continue to secrete sodium, chloride, and water, but, in the absence of sufficient viable mature enterocytes, this fluid can no longer be reabsorbed. To obtain support for our hypothesis, we measured the unidirectional fluxes of sodium across the ischaemic mucosa with the aid of ${ }^{22} \mathrm{Na}$, and we were able to demonstrate (Table 3) that the secretion is the result of a tremendous inhibition of the absorptive flux of sodium, the secretory flux being almost unchanged. If the secretion in fact resulted from filtration across the damaged mucosa, ${ }^{48}$ one would expect to find an increase in the secretory flux of sodium. Let us now consider the case of the protected ischaemic intestine: in this situation the number of mature enterocytes on the sides of the villi suffice to neutralise the net secretion that occurs in the crypts, but are insufficient to achieve net absorption of sodium and water; this explanation is corroborated by the existence in such tissues of a finite, albeit reduced, capacity for amino-acid transport, which is a property of the mature enterocytes and provides an indication of the number of such cells that have survived the trauma.

Table 3 Net and unidirectional fluxes in normal and ischaemic intestine

\begin{tabular}{lllll}
\hline & Control loop & Ischaemic loop & \multicolumn{2}{c}{ Statistical inference } \\
\cline { 3 - 4 } & & & $t$ & P \\
\hline Net water movements & $4 \cdot 5 \pm 0.49$ & $-1.8 \pm 0.28$ & $11 \cdot 2$ & $<0.001$ \\
Net sodium movements & $690 \pm 82$ & $-280 \pm 48$ & 10.3 & $<0.001$ \\
Net potassium movements & $25 \pm 3 \cdot 8$ & $-14 \pm 0.9$ & 9.87 & $<0.001$ \\
Sodium flux lumen-blood & $950 \pm 84$ & $120 \pm 31$ & 9.29 & $<0.001$ \\
Sodium flux blood-lumen & $260 \pm 20$ & $400 \pm 65$ & 2.09 & $\mathrm{NS}$ \\
\hline
\end{tabular}

Ileal loops of six dogs were perfused with Krebs bicarbonate buffer containing $0.2 \%$ glucose and labelled with a tracer dose of ${ }^{22} \mathrm{Na}$. In six other dogs, the experimental loop was first rendered ischaemic for one hour, and then perfused with the same medium. Net movements of sodium and potassium were assessed by flame photometry (a negative sign indicates net movements from the blood into the lumen), and the unidirectional flux from lumen to blood was calculated from the disappearance of the isotope. The movement from blood to lumen was evaluated as the difference between the two determinations. Ion fluxes expressed in $\mu \mathrm{mol} / \mathrm{h} / \mathrm{g}$ dry tissue and water movements in $\mathrm{ml} / \mathrm{h} / \mathrm{g}$ dry tissue. Results are means \pm SEM, statistical analysis being performed by means of the $t$ test for unpaired data (NS : not significant at the $5 \%$ level). (Reproduced with permission. ${ }^{17}$ ) 
This hypothesis provides an explanation for a puzzling feature of the mucosa during the course of regeneration following ischaemia-namely, the fact that the recovery of water and ion absorption in vivo is always retarded in comparison with the restoration of active transport capacity for sugars and amino-acids in vitro. ${ }^{16}$ In the first stages of regeneration, as we have seen, a new epithelial covering, capable of absorbing organic solutes, is formed, but the villi are considerably shorter than normal during this phase, and for this reason they possess a numerically smaller population of mature enterocytes. Therefore the proportion of crypt to villus cells is modified in favour of the former; there are sufficient mature enterocytes to reabsorb the fluid secreted in the crypts but not enough to ensure net absorption of water and sodium. The same concept can be invoked to resolve other pathophysiological situations: it explains, for instance, how the jejunum of patients with coeliac disease is able to absorb glucose in vivo in the presence of a net secretion of sodium and water, ${ }^{52}$ despite the well-known relationship between intestinal sodium and glucose transports. In this situation, the abundant secretion occurring in the lengthened crypts cannot be neutralised by the reduced absorptive capacity of the stunted villi, but the villus cells are nevertheless capable of a finite absorption of glucose. The observation that glucose added to the perfusate significantly reduces sodium secretion, presumably by stimulating the absorptive flux of the cation, provides additional support for this interpretation..$^{53}$ The work of these last authors, which demonstrates that prostaglandins elicit markedly less secretion in coeliac patients than in normal subjects, may, at first sight, appear to contradict our hypothesis, but, on reflection, it is seen to be perfectly compatible with it: if both crypt and villus cells possess both absorptive and secretory mechanisms, and if prostaglandins can stimulate the secretory mechanism in both cell types, then the hormone would clearly have a less dramatic effect in a mucosa with a much smaller overall number of cells, as occurs in sprue.

In an attempt to verify our hypothesis, we have induced intestinal lesions in other ways. ${ }^{17}$ By perfusing the dog intestine in vivo with a solution of Triton X-100, we caused desquamation of the enterocytes from the tips of the villi, but the extent of the lesions was less than that resulting from ischaemia. In these circumstances, the transport of sugars and amino-acids in vitro was reduced but not abolished. As predicted by our hypothesis, the net absorption of water and electrolytes was reduced to zero, but net secretion was not established. The concept may also be supported with the aid of studies of other investigators: pronounced desquamation of villus enterocytes is elicited by the intraluminal administration of Clostridium perfringens enterotoxin ${ }^{54}$ this is associated with a large reduction in the absorption of glucose by the intestine in vivo and the development of a profuse secretion of water and electrolytes towards the lumen. In view of the metabolic alterations that occur in this tissue, ${ }^{65}$ this secretion is probably also the result of a strong reduction in the absorptive flux of sodium. Note that the mode of action of this toxin contrasts markedly with that of cholera toxin which specifically stimulates the secretory flux of sodium, which causes no structural damage to the mucosa, and which is even capable of stimulating the accumulation of sugars and amino-acids in vitro. ${ }^{56}$ 
Chronic ischaemia of intestine

Despite the frequency with which arteriosclerotic lesions of the digestive arteries are encountered clinically, as revealed by anatomopathological or arteriographic studies, syndromes of chronic ischaemia are rare..$^{34} \mathbf{5 7}$ One manifestation is intestinal angina, characterised by intense postprandial pains in the abdomen. In patients with this syndrome, the intestinal blood flow is reduced to low levels; it suffices to maintain the integrity of the resting intestine, but, during the digestive phase, when the organ requires a greater supply of oxygen, the resistance offered by the partially obliterated vessels is such that the blood flow cannot be increased in response to the requirements of the mucosa, which accordingly suffers temporary ischaemia. The medical and surgical treatment of such patients has been discussed in detail by Marston. ${ }^{34}$

In view of the rarity with which chronic ischaemia is encountered clinically, despite the abundance of vascular sclerosis in the splanchnic bed, it is not surprising that no convincing description of experimental chronic ischaemia exists in the literature. In one attempt at inducing such a syndrome, Stanley, Brink, and Fry ${ }^{58}$ placed constrictors around the superior mesenteric and coeliac arteries; after arteriographic control to verify the obliteration of the vessels in question, the authors claimed that the animals suffered from a malabsorption syndrome following occlusion of the coeliac artery. These conclusions are suspect for three reasons: first, the authors used xylose absorption as a functional parameter, though this is now widely agreed to be a poor indicator of intestinal function; ${ }^{59}$ secondly, they observed a significant difference in xylose absorption after occlusion of the coeliac artery, but not after the far more serious intervention represented by the simultaneous obliteration of coeliac and superior mesenteric vessels; and, thirdly, they presented no histological control of the state of the tissue. In criticising this work, we wish to emphasise the difficulties inherent in the study of a pathophysiological condition of the intestine without simultaneous examination of structure and function of the organ.

In our laboratory, we have used several methods in the attempt progressively to reduce the intestinal circulation and we have never met with any success. Our experience has led us to conclude that the response of the intestine to oxygen lack is a matter of all or nothing. The ready development of collateral circulation permits the mucosa to withstand all but the most severe ischaemic attacks. Clearly, to mimic intestinal angina in arteriosclerotic patients, it would be necessary to induce generalised vascular lesions, a situation that has not been reproduced up to the present time. Obliteration of one or more vessels in a normal animal will never have the same effect.

\section{Response of large intestinal mucosa to ischaemia}

In the clinic, ischaemic accidents are much more common at the level of the colon than in the small intestine. The reason for this situation is simple, but it was overlooked for a long time. ${ }^{34}$ We have already 
seen that arteriosclerotic lesions of the mesenteric vessels are relatively common, but they are rarely serious in the small intestine, because of the tremendous compensatory capacity of the collateral network. However, in the colon, there exist certain regions, such as Griffith's point in the splenic flexure, where sufficient collateral circulation cannot develop after partial obstruction of a large vessel. ${ }^{57}$ Ischaemic accidents in this area are particularly common in elderly patients with a history of arteriosclerosis and cardiac arrhythmia. In addition, ischaemia of the colon may arise during surgical interventions on the lower aorta which require temporary or permanent clamping of the inferior mesenteric artery. ${ }^{60}$

Ischaemic colitis can follow three courses, depending on the severity of the insult: (1) after short temporary ischaemia of a colonic segment, such as occurs as a result of temporary clamping of the inferior mesenteric artery, the mucosa can heal spontaneously without leaving any sequelae; (2) after a longer period of ischaemia in which the underlying muscular layers are also affected, stenosis may develop; the muscular layers become fibrotic and are covered with a matrix of granulation tissue, with or without islets of mucosa; surgical removal of the stenotic region is not generally necessary; (3) after prolonged acute ischaemia, necrosis and gangrene may develop throughout the colonic wall. In view of the serious risk of perforation and peritonitis, the affected segment should be removed surgically as rapidly as possible.

In spite of its clinical importance, colonic ischaemia has been the subject of far fewer experimental studies than the corresponding lesions of the small intestine. Nevertheless, all investigators who have worked with the dog colon have emphasised the close parallel between clinical and experimental observations. ${ }^{61-64}$ In particular, Marston et al. ${ }^{62}$ tied off different vessels, either alone or in combination, and managed to reproduce, according to radiological and histopathological criteria, the different stages of ischaemic colitis enumerated above. In the same vein, Boley et al., ${ }^{65}$ in a series of elegant experiments, injected microspheres of different diameters into the afferent vessels of the colon, and described different radiological lesions as a function of the size of the injected spheres.

Functional and morphological examinations of the ischaemic colon have led to the conclusion that this mucosa is much less sensitive to ischaemia than that of the small intestine. ${ }^{6286} 67$ In addition, once damaged, the colonic mucosa regenerates more slowly. These conclusions are based on studies of mucosal structure and function during recovery, but it should be remembered that the number of experimental studies performed on this tissue is strictly limited, and that certain fundamental tests, such as the exploration of water and sodium movements in vivo, have never been performed in the ischaemic colon.

In our laboratory, we have followed the loss and restoration of the function of dog colon mucosa after acute ischaemic traumas of one, two or three hours, and we have correlated the functional events with the histological picture of the organ. As functional parameters, we first used the capacity of the tissue to transport radioactive sodium across sheets of mucosa in vitro and the specific activities of $\mathrm{Na}^{+}-\mathrm{K}^{+}$-ATPase in 
microsomal fractions derived from mucosal homogenates. ${ }^{21}{ }^{67}$ Later, we observed that dog colon mucosa was capable of accumulating amino-acids and sugars against concentration gradients by sodium- and energydependent mechanisms, analogous to those of the small intestine. ${ }^{68}$ This property was not shared by the colons of other species, but permitted us, when working with the dog, to develop a much more sensitive functional test-namely, the measurement of the distribution ratio developed for these two classes of substrate between intra- and extra-cellular compartments. This test was used to assess the changes induced in the dog colon mucosa after an ischaemia of one hour: only superficial lesions occur, accompanied by a slight reduction in functional capacity, and almost complete recovery is observed one day later. ${ }^{69}$

In a single study of the response of the rat colon to ischaemia, Rijke and $\mathrm{Gart}^{70}$ examined cell kinetics after an ischaemia of 90 minutes, and they were able to demonstrate the development of an accelerated proliferation during the recovery phase, although the proliferative compartment was not enlarged. Recovery was again complete 24 to 48 hours after the trauma. The accelerated proliferation also finds an analogy in the small intestine, where the same phenomenon has been observed after short periods of ischaemia in the rat. ${ }^{37}$

After an ischaemia of two hours in the dog colon, seven days are necessary for complete functional recovery, as gauged by studies on transmural sodium transport (Table 1). In this study, the response of the ileum and the colon to the same trauma was directly compared: it was seen that, although the colon did not appear to suffer such severe damage after the acute ischaemia, it nevertheless recovered more slowly. Even after one week, when the functional tests were normal, discrete ulcers, visible on the microscopic slides, nevertheless remained, though they apparently did not affect the biochemical results. ${ }^{21}$

In all the studies quoted, the damage caused by these short periods of total ischaemia were readily reversible within a short time. The lesions caused by an acute ischaemia of the dog colon lasting three hours are considerably more severe and the response of the dogs was rather varied. ${ }^{67}$ In some cases, structural and functional recovery was complete within two to four weeks, whereas in others the lesions evolved towards stenosis of the colonic wall, as is sometimes encountered clinically. ${ }^{63}$ In one case, the muscularis mucosae had clearly been damaged by the trauma and had not regenerated, even though the mucosa had recovered completely and rested directly on the submucosal tissue. Another group of dogs died with perforations of the colonic wall, particularly in the region in which the clamps had originally been placed; in these cases, the organ revealed itself as frankly necrotic, even gangrenous. The heterogeneity in the response encountered in this series of experiments may be partly ascribed to different degrees of damage inflicted on the vascular wall by the clamps. If revascularisation was complete at the moment the clamps were released, it is probable that the organ would recover. But, if the circulation remained precarious after removal of the clamps, because of some intrinsic damage to the vessels caused by the prolonged clamping, then the ischaemic period clearly lasted for more than the prescribed three hours, with dire consequences for the possible recovery of the colon. 


\section{Conclusions}

In this article we have reviewed experimental studies on intestinal and colonic ischaemia, and we have underlined the close correlations between experimental observations and clinical practice. We have emphasised the rapidity with which ischaemic destruction sets in, but we are bound to admit that the underlying biochemical mechanisms by which tissue disruption is initiated are still far from clear. As it is certainly possible to protect the organ from ischaemic damage, at least to a certain extent, it is important to understand the basic mechanism of destruction, in order to develop more efficient means of protection.

J W L ROBINSON, V MIRKOVITCH, B WINISTÖRFER, AND F SAEGESSER

\section{Département de Chirurgie Expérimentale \\ Service Universitaire de Chirurgie $A$ \\ Centre Hospitalier Universitaire Vaudois \\ Lausanne, Switzerland}

Received for publication 11 December 1980

\section{References}

${ }^{1}$ Brown RA, Chiu C-J, Scott HJ, Gurd FN. Ultrastructural changes in the canine ileal mucosal cell after mesenteric arterial occlusion. Arch Surg 1970; 101:290-7.

2Röttger P, Schneider M, Huebner K, Zeeb K, Gimnich J. Investigations on the enzyme content, the ultrastructure and the regeneration of the upper jejunum of the rat following temporary total ischaemia. In: Varró V, Bálint GA eds. Current views in gastroenterology. Budapest: Hungarian Society of Gastroenterology Press, 1977; 1:127-41.

3 Várkonyi T, Wittman T, Varró V. Effect of local circulatory arrest on the structure of the enterocytes of the isolated intestinal loop. Digestion 1977; 15:295-302.

${ }^{4}$ Chiu C-J, McArdle AH, Brown R, Scott HJ, Gurd FN. Intestinal mucosal lesion in low-flow states. I. A morphological, hemodynamic and metabolic reappraisal. Arch Surg 1970; 101:478-83.

${ }^{5}$ Menge H, Robinson JWL. Early phase of jejunal regeneration after short term ischemia in the rat. Lab Invest 1979; 40:25-30.

'Wagner R, Gabbert H, Höhn P. The mechanism of epithelial shedding after ischemic damage to the small intestinal mucosa. A light and electron microscopic investigation. Virchows Arch [Cell Pathol] 1979; 30:25-31.

${ }^{7}$ Khanna SD. An experimental study of mesenteric occlusion. J Path Bact 1959; 77:575-90.

${ }^{8}$ Glotzer DJ, Villegas AH, Anekamaya S, Shaw RS. Healing of the intestine in experimental bowel infarction. Ann Surg 1962; 155:183-90.

${ }^{9}$ Robinson JWL, Antonioli J-A, Mirkovitch V. The intestinal response to ischaemia. Naunyn-Schmiedebergs Arch Pharmacol 1966; 255:178-91.

${ }^{10}$ Rao NS, Wynn-Williams A. Normal and ischaemic jejunal mucosa of mice: scanning electron microscope study. J Micr (Paris) 1972; 15:219-24.

${ }^{11}$ Robinson JWL, Mirkovitch V. The recovery of function and microcirculation in small intestinal loops following ischaemia. Gut 1972; 13:784-9.

${ }^{12}$ Gabbert H, Wagner R, Aust P, Höhn P. Ischemia and post-ischemic regeneration of the small intestinal mucosa. An enzyme-histochemical investigation. Acta Histochem 1978; 63:197-213.

${ }^{13}$ Röttger P, Oran M. Histochemische und biochemische Untersuchungen zur Frage des Enzym-Gehaltes der Dünndarmschleimhaut nach temporärer Ischämie. Verh dtsch Ges Pathol 1969; 53:189-95.

${ }^{14}$ David H, Uerlings I. Elektronenmikroskopische Befunde am Dünndarm des Kaninchens nach Gefassunterbindung. Exp Pathol 1967; 1:30 44. 
${ }^{15}$ Guthrie JE, Quastel JH. Absorption of sugars and amino acids from isolated surviving intestine after experimental shock. Arch Biochem 1956; 62:485-96.

${ }^{16}$ Robinson JWL, Menge H, Sepúlveda FV, Cobo F, Mirkovitch V. The functional response of the dog ileum to one hour's ischaemia. Clin Sci Molec Med 1976; 50:115-22.

${ }^{17}$ Robinson JWL, Winistörfer B, Mirkovitch V. Source of net water and electrolyte loss following intestinal ischaemia. Res Exp Med 1980; 176:263-75.

${ }^{18}$ Bounous G, Menard D, de Medicis E. Role of pancreatic proteases in the pathogenesis of ischemic enteropathy. Gastroenterology 1977; 73:102-8.

${ }^{19}$ Bounous $\mathrm{G}$, Konok G. Intestinal brush border enzymes after short-term mesenteric ischemia. Am J Surg 1977; 133:304-6.

${ }^{20}$ Stirling CE. Radioautographic localization of sodium pump sites in rabbit intestine. J Cell Biol 1972; 53:704-14.

${ }^{21}$ Robinson JWL, Haroud M, Winistörfer B, Mirkovitch V. Recovery of function and structure of dog ileum and colon following two hours' acute ischaemia. Europ $J$ Clin Invest 1974; 4:443-52.

22Riecken EO, Stewart JS, Dowling RH. Neuere Methode in der Diagnostik intestinaler Störungen. Internist 1966; 7:209-17.

${ }^{23}$ Sutherland NG, Bounous G, Gurd FN. Role of intestinal mucosal lysosomal enzymes in the pathogenesis of shock. J Trauma 1968; 8:350-80.

${ }^{24}$ Manohar M, Tyagi RPS. Experimental intestinal ischemia shock in dogs. Am J Physiol 1975; 225:887-92.

${ }^{25}$ Abe H, Carballo J, Appert HE, Howard JM. The release and fate of the intestinal lysosomal enzymes after acute ischemic injury of the intestine. Surg Gynec Obstet $1972 ; 135: 581-5$.

${ }^{26}$ Clermont HG, Williams JS. Lymph lysosomal enzyme acid phosphatase in hemorrhagic shock. Ann Surg 1972; 176:90-6.

${ }^{27}$ Courtice FC, Adams EP, Shannon AD, Bishop DM. Acid hydrolases in the rabbit in haemorrhagic shock. $Q J$ Exp Physiol 1974; 59:31-42.

${ }^{28}$ Bounous G, McArdle AH. Release of intestinal enzymes in acute mesenteric ischemia. J Surg Res 1969; 9:339-46.

${ }^{29}$ Haglund U, Lundholm K, Lundgren O, Scherstén T. Intestinal lysosomal enzyme activity in regional simulated shock: Influence of methylprednisolone and albumin. Circ Shock 1977; 4:27-34.

${ }^{30}$ Wagner R, Gabbert $\mathbf{H}$, Höhn P. Ischemia and post-ischemic regeneration of the small intestinal mucosa. A light microscopic and autoradiographic study. Virchows Arch [Cell Pathol] 1979; 31:259-76.

${ }^{31}$ Bounous G, Proulx J, Konok G, Wollin A. The role of bile and pancreatic proteases in the pathogenesis of ischemic enteropathy. Int J Clin Pharmacol Biopharm 1979; 17:317-23.

${ }^{32}$ Cameron GR, Khanna SD. Regeneration of intestinal villi after extensive mucosal infarction. J Path Bact 1959; 77:505-10.

${ }^{33}$ Pitha J. The fine structure of regenerating epithelium in the small intestine. Virchows Arch [Cell Pathol] 1971; 7:314-41.

${ }^{34}$ Marston A. Intestinal Ischaemia. London: Arnold, 1977.

${ }^{35}$ Mirkovitch V, Robinson JWL, Menge H, Cobo F. The consequences of ischaemia after mechanical obstruction of the dog ileum. Res Exp Med 1976; 168:45-55.

${ }^{36}$ Eastwood GL. Gastrointestinal epithelial renewal. Gastroenterology 1977; 72:962-75.

${ }^{37}$ Rijke RPC, Hanson WR, Plaisier HM, Osborne JW. The effect of ischemic villus cell damage on crypt cell proliferation in the small intestine. Evidence for a feedback control mechanism. Gastroenterology 1976; 71:786-92.

${ }^{38}$ Chiu C-J, Scott HJ, Gurd FN. Intestinal mucosal lesion in low-flow states. II. The protective effect of intraluminal glucose as energy substrate. Arch Surg 1970; 101:484-8.

${ }^{39}$ A hrén C, Haglund U. Mucosal lesions in the small intestine of the cat during low flow. Acta Physiol Scand 1973; 88:541-50.

${ }^{40}$ Mirkovitch V, Menge H, Robinson JWL. Protection of the intestinal mucosa during ischaemia by intraluminal perfusion. Res Exp Med 1975; 166:183-91.

${ }^{41}$ Robinson JWL, Mirkovitch V. The roles of intraluminal oxygen and glucose in the protection of the rat intestinal mucosa from the effects of ischaemia. Biomedicine 1977; 27:60-2. 
${ }^{42}$ Bounous G. Role of the intestinal contents in the pathophysiology of acute intestinal ischemia. Am J Surg 1967; 114:368-75.

${ }^{43}$ McArdle AH, Chiu C-J, Gurd FN. Intraluminal glucose, substrate for ischemic intestine. Arch Surg 1972; 105:441-5.

${ }^{44}$ Shute $\mathrm{K}$. Effect of intraluminal oxygen on experimental ischaemia of the intestine. Gut 1976; 17:1001-6.

${ }^{45}$ Luisier A-L, Robinson JWL. Glycolysis as an energy source for intestinal transport of amino acids: Comparison between rat and guinea-pig. Comp Biochem Physiol $[A]$ 1975; 51:105-9.

${ }^{46}$ Hueckel HJ, Chiu C-J, Hinchey EJ. The effect of intraluminally administered glucose in reducing fluid and electrolyte loss from the ischemic intestine. Surg Gynec Obstet 1973; 136:780-4.

${ }^{47}$ Frauchiger JP. Resorptions- und Sekretionsstudien am ischämisch geschädigten Hundedünndarms. Helv Chir Acta 1975; 42:101.

${ }^{48}$ Cook BH, Wilson ER, Taylor AE. Intestinal fluid loss in hemorrhagic shock. Am J Physiol 1971; 221:1494-8.

${ }^{49}$ Robinson JWL, Mirkovitch V, Menge $\mathrm{H}$. Consequences of the destruction of the villus epithelium by ischaemia or Triton X-100. Gut 1977; 18:425.

${ }^{50}$ Bounous G. Metabolic changes in the intestinal mucosa during hemorrhagic shock. Can J Surg 1965; 8:332-9.

51 Kingham JGC, Whorwell PJ, Loehry CA. Small intestinal permeability. I. Effects of ischaemia and exposure to acetyl salicylate. Gut 1976; 17:354-61.

${ }^{52}$ Bloch R, Menge H, Lingelbach B, Lorenz-Meyer H, Haberich FJ, Riecken EO. The relationship between structure and function of small intestine in patients with a sprue syndrome and in healthy controls. Klin Wschr 1973; 51:1151-8.

${ }^{53}$ Modigliani R, Matuchansky C, Bernier J-J. Depressed jejunal secretion of water and ions in response to prostaglandin $\mathrm{E}_{1}$ in adult celiac disease. Dig Dis Sci 1979; 24:763-8.

${ }^{54} \mathrm{McD}$ nel JL, Duncan CL. Regional localisation of activity of Clostridium perfringens type A enterotoxin in the rabbit ileum, jejunum, and duodenum. J Infect Dis 1977; 136:661-6.

${ }^{55} \mathrm{McDonel} \mathrm{JL}$, Duncan CL. Effects of Clostridium perfringens enterotoxin on metabolic indexes of everted rat ileal sacs. Infect Immun 1975; 12:274-80.

${ }^{56}$ Robinson JWL, Mirkovitch V, Sepúlveda FV, Menge H. Enhanced non-electrolyte uptake in vitro by the dog jejunal mucosa in the cholera-toxin-induced secretory phase. J Physiol (Paris) 1977; 73:5-12.

${ }^{57}$ Saegesser F, Roenspies U, Robinson JWL. Ischemic diseases of the large intestine. Pathobiol Ann 1979; 9:303-37.

${ }^{58}$ Stanley JC, Brink BE, Fry WJ. Experimental intestinal ischaemia: provocative absorption studies following gradual celiac and superior mesenteric artery occlusion. J Surg Res 1973; 14:133-8.

${ }^{59}$ Menge $\mathrm{H}$, Gottesbüren $\mathrm{H}$, Riecken EO. Zum diagnostischen Aussagewert von segmentaler Perfusionsmethode, Fettbilanz und indirekten Dünndarmfunktionstests. Vergleichende Untersuchungen. Dtsch med Wschr 1973; 98:2397-402.

${ }^{60}$ Smith RF, Szilagyi DE. Ischemia of the colon as a complication in the surgery of the abdominal aorta. Arch Surg 1960; 80:806-21.

${ }^{61 B o l e y ~ S J, ~ S c h w a r t z ~ S, ~ L a s h ~ J, ~ S t e r n h i l l ~ V . ~ R e v e r s i b l e ~ v a s c u l a r ~ o c c l u s i o n ~ o f ~ t h e ~}$ colon. Surg Gynec Obstet 1963; 116:53-60.

${ }^{62}$ Marston A, Marcuson RW, Chapman M, Arthur JF. Experimental study of devascularisation of the colon. Gut 1969; 10:121-30.

${ }^{03}$ Rausis C, Robinson JWL, Mirkovitch V, Saegesser F. Désordres vasculaires du gros intestin: données expérimentales et corrélations cliniques. Helv Chir Acta 1973; 40:295-305.

${ }^{64}$ Parks TG. Experimental non-gangrenous mesenteric ischaemia. Acta Gastroentérol Belg 1974; 37:529-38.

${ }^{65}$ Boley SJ, Krieger H, Schultz L, et al. Experimental aspects of peripheral vascular occlusion of the intestine. Surg Gynec Obstet 1965; 121:789-94.

${ }^{166}$ de Villiers DR. Ischaemia of the colon: an experimental study. Br J Surg 1966; 53:497-503.

${ }^{67}$ Robinson JWL, Rausis C, Basset P, Mirkovitch V. Functional and morphological response of the dog colon to ischaemia. Gut 1972; 13:775-83. 
${ }^{68}$ Robinson JWL, Luisier A-L, Mirkovitch V. Transport of amino-acids and sugars by the dog colonic mucosa. Pflügers Arch 1973; 345:317-26.

${ }^{69}$ Robinson JWL, Menge H, Mirkovitch V. The response of the dog colon to one hour's ischaemia. Res exp Med 1975; 165:127-34.

${ }^{70}$ Rijke RPC, Gart R. Epithelial cell kinetics in the descending colon of the rat. I. The effect of ischaemia-induced epithelial cell loss. Virchows Arch [Cell Pathol] 1979; 31:15-22. 